\title{
Extreme climatic events over Vietnam from observational data and RegCM3 projections
}

\author{
Thi-Minh-Ha Ho ${ }^{1, *}$, Van-Tan Phan ${ }^{1}$, Nhu-Quan Le ${ }^{2}$, Quang-Trung Nguyen ${ }^{1}$
}

\author{
${ }^{1}$ Department of Meteorology, Hanoi University of Science, 334 Nguyen Trai Street, Thanh Xuan District, Hanoi, Vietnam \\ ${ }^{2}$ Institute of Geophysics, Vietnam Academy of Science and Technology, 18 Hoang Quoc Viet Street, Cau Giay District, \\ Hanoi, Vietnam
}

\begin{abstract}
Extreme climatic events, including hot days, cold nights and heavy rainfall days, were analysed for 7 climatic sub-regions in Vietnam, based on historical observed data and climate projections of the International Center for Theoretical Physics regional climate model version 3 (RegCM3). Firstly, historical observed data sets covering 1961-2007 were analyzed to detect extreme events and their decade-by-decade trends. Extreme events and their changes are quite different over the 7 sub-regions, owing to their different local climate. Secondly, the extremes of each sub-region detected from the simulation of RegCM3 for the baseline period 1980-1999 were applied to the projection in the years 2001-2050, based on the IPCC SRES A1B and A2 scenarios, to reveal the changing trend of extremes in the future. The RegCM3 projections indicate that, in general, hot summer days will increase and cold winter nights will decrease as a consequence of global warming. The rainy season heavy rainfall events tend to decrease for all sub-regions except for 2, in northwest and south-central Vietnam. Strong opposite projected changes in precipitation extremes over the southern half of Vietnam seem to be linked to changes in southwesterly air flow from the Bay of Bengal and the number of strong tropical cyclones coming from the South China Sea and the NW Pacific.
\end{abstract}

KEY WORDS: Detection · Extreme events $\cdot$ Regional climate model $\cdot$ RegCM $\cdot$ Scenarios $\cdot$ Vietnam

\section{INTRODUCTION}

Climate extremes are events such as heat waves, cold surges, frosts, floods, droughts and severe storms, which cause great damage to ecological systems and human beings (Meehl et al. 2000). The damage of disproportionate economic and/or social disruption in the area affected by such events depends on the intensity and frequency of extremes (Wisner et al. 2004). The US Environmental Protection Agency (www.epa.gov/climatechange/effects/extreme.html) noted that if the frequency of warm spells/heat waves increases over most land areas in the future, it may reduce yields in warmer regions because of heat stress at key development stages. In addition, it may increase water demand and cause water quality prob- lems, e.g. algae blooms. Heat waves increase the risk of heat-related mortality and reduce the quality of life for people in warm areas without air conditioning. Precipitation extremes may cause floods and landslides, damage to crops, soil erosion, inability to cultivate land, and water-logging of soils. They may also affect the quality of surface- and groundwater, influence the contamination of water supplies, and result in death, injury, infectious disease, allergies and dermatitis. This damage is several times higher after storms, especially over tropical regions. The Fourth Assessment Report of the IPCC (IPCC 2007) stated that '... changes in some types of extreme events have already been observed, for example, increases in the frequency and intensity of heat waves and heavy precipitation events'. 
In Vietnam, temperature extremes are commonly defined according to temperature thresholds which affect human health. These comprise temperatures $\geq 35^{\circ} \mathrm{C}$ or $<13-15^{\circ} \mathrm{C}$, as defined by the Vietnamese National Weather Service Center. Cold extremes usually occur in the northern part of Vietnam, where temperature in winter is $4-5^{\circ} \mathrm{C}$ lower than the zonal average (Pham \& Phan 1993), due to severe cold surges, whereas over the southern part of Vietnam, where average temperatures are very high in summer, heat waves often occur. The latter will occur more often in the context of global warming (IPCC 2007, Trenberth et al. 2007). IPCC (2007) stated that the global average temperature has increased by $0.74 \pm 0.18^{\circ} \mathrm{C}$ in the period $1906-2005$, and Asia became warmer by $0.3-0.8^{\circ} \mathrm{C}$ in the last $100 \mathrm{yr}$. For Vietnam, warming of $0.5-0.7^{\circ} \mathrm{C}$ was observed in the last 50 yr (1958-2007; Vietnamese Ministry of Natural Resources and Environment 2009).

Global warming affects extreme precipitation (McInnes \& Hubbert 1996, Francis \& Hengevelt 1998, Tompkins 2002). Tropospheric warming will increase the atmospheric water-holding capacity by approximately $7 \% \mathrm{~K}^{-1}$ following the Clausius-Clapeyron equation, thereby potentially increasing extreme precipitation (Trenberth et al. 2003, Liu et al. 2009). Precipitation extremes over Vietnam are mostly associated with storms and tropical cyclones over the South China Sea and coming from the northeast Pacific Ocean. In this respect, the storm season in 2008 might be an example of future extreme events in Vietnam. In 2008, the number of tropical cyclones and storms having influence an on Vietnam was greater than the climatologic value, their speed was faster, and their intensity changed more abnormally than observed previously (VNWSC 2008). The storms in 2008 caused a lot of damage and deaths, thereby emphasizing that detection of extreme climate and/or precipitation is a significant issue in Vietnam.

Many climate studies are focusing on the historical trends of climate extreme events and the possible links between those trends and projections of global warming (Karl \& Easterling 1999, Solow 1999, Groisman et al. 1999, Hegerl et al. 2006, Alexander et al. 2006). For example, the number of frost events have decreased in Australia and New Zealand and the minimum daily temperatures has increased (Plummer et al. 1999). Globally, the numbers of warm days and nights are increasing faster in some regions than in others; the number of heavy precipitation days in the southcentral USA and parts of South America has increased, while the number of consecutive dry days has decreased throughout parts of India (Alexander et al. 2006). However, the greatest barrier to uncovering historical trends of extremes is the imperfect climate data in terms of record length, accuracy and the distribution of climate stations. These limitations are obvious over several regions in Asia, in particular Vietnam. Manton et al. (2001) documented the trends of temperature and precipitation as well as the changes of hot days and cold nights during 1961-1998 of 13 countries in Southeast Asia and the southern Pacific. However, because of the paucity of observation data (only 3 observation stations: Phulien, Playcu and Vanly), the trends of these extreme events over Vietnam were incomplete and vague. Using daily precipitation data from Southeast Asian countries, Endo et al. (2009) investigated trends in precipitation extremes during the 1950s to the 2000s and found that heavy precipitation increased in southern Vietnam while it decreased in northern Vietnam. They calculated 12 rainfall indices, including total annual precipitation, number of days per year with precipitation $>50 \mathrm{~mm}$, and annual precipitation above the 95th and 99th percentiles of the daily rainfall.

Giorgi et al. (2001) used coupled atmosphereocean general circulation models (AOGCMs) to show that in addition to the maximum winter warming in northern high latitudes, the summer warming over Central Asia, Tibet and the Mediterranean regions will be much greater than the global average. Their results also indicated an increase in South Asia and East Asia summer monsoon precipitation. However, the use of coarse resolution AOGCMs to investigate changes in extremes over Vietnam is not appropriate because of Vietnam's narrow east-west extent, its complex topography and heterogeneous climate regimes. Here, regional climate models (RCMs) are better suited, as they can give improved and more detailed results than global models (e.g. Giorgi 2006), especially with regard to capturing extreme events. RCMs have been used to investigate the occurrence of past extremes, e.g. over Europe (Sánchez et al. 2004) and Australia (Pitman \& Perkins 2008). Halenka et al. (2006) analyzed daily precipitation and temperature extremes simulated for the period 19612000 over the Czech Republic, Bell et al. (2004) considered future changes in extremes over California, Diffenbaugh \& Ashfaq (2010) analyzed the projected changes in hot extremes over the USA, and Im et al. $(2007 \mathrm{a}, \mathrm{b})$ investigated the characteristics and potential future changes of different extreme climate indices over the Korean Peninsula. In Vietnam, numerical climate models have been introduced for approximately a decade, but most of their applica- 
tions have been for seasonal simulations only (Ho 2008, Phan et al. 2009). Thus, the present study is one of the first efforts in Vietnam to detect climate extremes from historical observations and describe their potential future development from regional climate projections. This study is an important subproject of the Vietnamese National Funded Project titled The Impacts of Global Climate Change on Extreme Climate Events over Vietnam, Predictability and Adaptation Strategic Solutions (KC.08.29/06-10).

In the present study, we considered hot summer days, cold winter nights and heavy rainfall days as important climate extremes occurring over Vietnam. First, their past occurrence was analyzed from historical observational data over 7 climatic sub-regions of Vietnam. Then, their future changes up to 2050 were considered as projected by 2 scenario simulations of RegCM3, which was nested into a global climate simulation of the Community Climate System Model version 3 (CCSM3; Meehl et al. 2006).

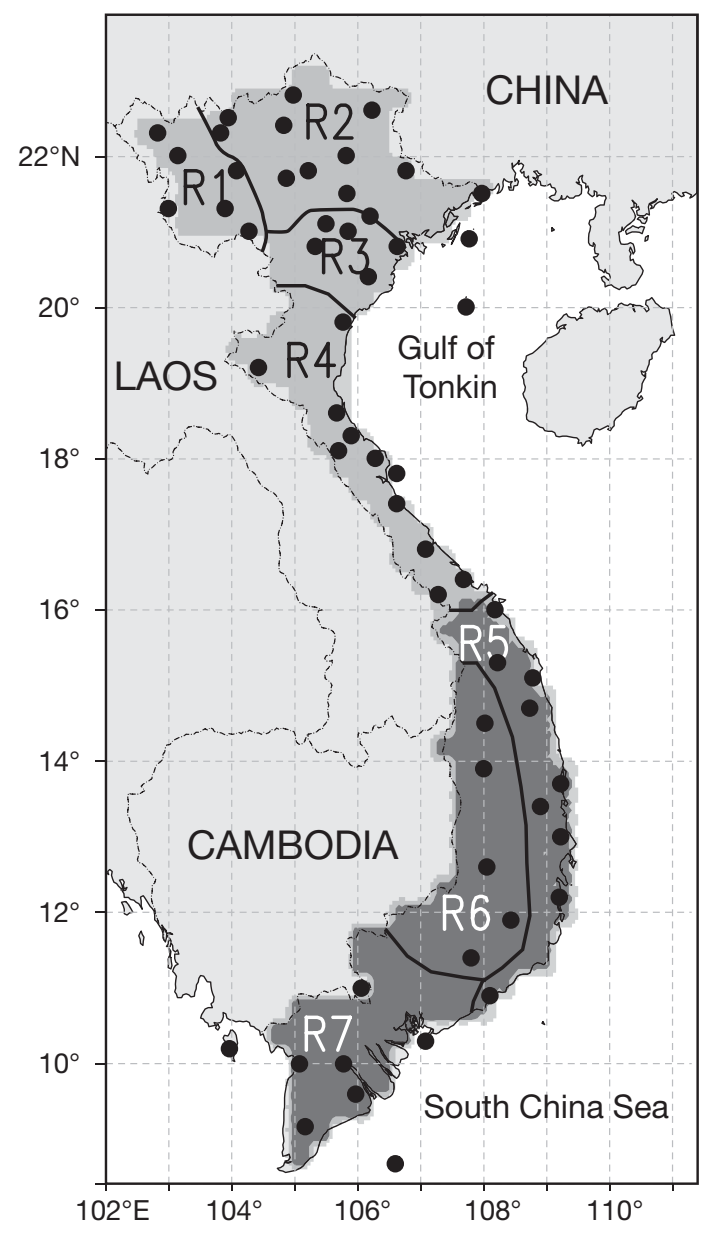

Fig. 1. The 58 observation stations $(\bullet)$ for the 7 climatic subregions used in this study, R1, R2, R3, R4 (light grey) and R5, R6, R7 (dark grey)

\section{DATA AND EXTREME INDICES}

We collected data from 58 observation stations in 1961-2007 and analyzed their changes over this period for 7 climatic sub-regions of Vietnam.

\subsection{Climate condition analysis and data selection}

Vietnam's terrain is characterized by a complicated topography (see Phan et al. 2009). In general, there are 2 types of climate in the 2 parts of Vietnam separated by the HaiVan Pass at $16^{\circ}$ N. However, depending on the local characteristics, the climate of Vietnam can be divided into 7 sub-regions (Nguyen \& Nguyen 2004), shown in Fig. 1.

From HaiVan Pass towards the north, climate is tropical and monsoonal with a cold winter. Because of the difference in winter rainfall, the southern part of this region (sub-region R4) is separated at $20^{\circ} \mathrm{N}$ from the northern part, which comprises the subregions R1, R2 and R3 (Fig. 1). Being under the effects of topography and monsoon, these 3 northern provinces have 4 distinct seasons including spring (February to early April), summer (late April to early September), autumn (late September to October) and winter (November to early February). Spring is the mildest season of the year over these sub-regions, and is fairly warm with little rainfall. In the summer, temperature and rainfall amounts are very high, with the highest temperatures often occurring in June and the largest rainfall rates in May and August. It is mild in autumn, but very dry and cold in winter. Subregion $\mathrm{R} 4$ has 4 similar seasons, but its winter is warmer and wetter because of the effect of the Truong Son Mountains at the boundary of Vietnam and Laos, blocking the northeast monsoon passing across the Gulf of Tonkin. However, the Truong Son Mountains are a barrier to the southwest monsoon causing an effect called 'foehn' in the sub-region R4, in which the monsoon rainfall completely occurs over the area in the west of the mountain before the remaining dry air passes over the mountains toward the east. Consequently, it is very hot and dry in summer over the coastal provinces of R4.

From $16^{\circ} \mathrm{N}$ towards the south, the climate is tropical and monsoonal with only 2 seasons, a dry and a rainy one. The coastal provinces of sub-region R5 (Fig. 1) are hot year-round but have a similar rainfall condition to that of sub-region R4 above. Sub-region R6, the TayNguyen highland, has a much lower temperature than surrounding areas but a rainfall season similar to that of sub-region R3. The last sub-region, 
R7, has the characteristic tropical and monsoon climate with 2 seasons, a hot and rainy season occurring over 6 summer months (May to October) and a cold and dry season occurring over 6 winter months (November to April). Temperature is high yearround, like sub-region $\mathrm{R} 5$, but the climatic conditions are more stable.

The rainy seasons of sub-regions R1-R3, R6 and R7 (Table 1) coincide with the active phase of the Asian monsoon. Meanwhile, the rainy season of subregions R4 and R5 occurs later by several months as a result of the 'foehn' effect in summer. It usually lasts from August to December with a peak in September as a consequence of tropical cyclones (occurring as typhoons) or storms coming from the west Pacific Ocean and the South China Sea. In order to analyze precipitation extremes over Vietnam, only the highest rainfall months are considered to comprise the respective rainy season for each sub-region. In the case of minimum and maximum temperatures, data are analyzed for winter and summer months, respectively.

\subsubsection{Observation data}

Daily data were collected, observational and restoration errors were eliminated, and missing data were identified. The data were spatially homogeneous, in that all stations of each sub-region have similar probability distributions and trends. Almost all observation stations of sub-regions R1-R4 have full data for 1961-2007. Several stations of R5-R7 only have data since 1977 . There were some changes in the measurement tools over time, but the data were corrected and assessed by the Vietnamese Meteorological Data Service Centre. Nevertheless, data quality control was conducted based on 3 principles: (1) comparing each value with its climatologic value for each station; (2) comparing the physical consistence between 2 or more variables; and (3) a

Table 1. Rainy season and months of highest rainfall for the 7 climatic sub-regions

\begin{tabular}{|lcc|}
\hline Sub-region & Rainy season & Highest rainfall \\
\hline R1 & Apr-Sep & Jun-Aug \\
R2 & Apr-Oct & Jun-Aug \\
R3 & May-Oct & Jul-Sep \\
R4 & Aug-Dec & Aug-Oct \\
R5 & Aug-Dec & Sep-Nov \\
R6 & May-Oct & Jul-Sep \\
R7 & May-Oct & Aug-Oct \\
\hline
\end{tabular}

spatial test for each value with that of adjacent stations. All suitable data were utilized in the calculation of percentiles and the detection of extreme climatic events.

\subsubsection{Model data}

RegCM3 is the third version of the International Centre for Theoretical Physics (ICTP) RCM, which originated from NCAR-RegCM (Pal et al. 2007). The dynamics of RegCM3 are based on the Penn State/ NCAR Mesoscale Model version 4 (MM4, Anthes et al. 1987) and use hydrostatic, sigma vertical coordinates and lateral boundary condition relaxation. The physics in RegCM3 include the radiation scheme of Kiehl et al. (1996), the BATS1E land surface model (Dickinson et al. 1993), a non-local planetary boundary layer scheme (Holtslag et al. 1990), the Grell convection scheme (Grell 1993) with the closure assumption of Arakawa \& Schubert (which is the most consistent convection scheme of RegCM3 for Southeast Asia; Ho 2008), the BATS1E ocean flux model and the SUBEX large-scale precipitation scheme (Pal et al. 2000).

To investigate future development of extremes over Vietnam, RegCM3 was used to simulate a control or baseline simulation (BAS) from 1980 to 1999 and 2 scenario simulations for 2001-2050. For all simulations, RegCM3 was nested into the respective global climate simulations of the CCSM3 (Meehl et al. 2006), in which RegCM3 was provided with averaged CCSM3 data every $6 \mathrm{~h}$. The 2 projections followed the IPCC SRES A1B and A2 scenarios, respectively. RegCM3 was set up with a configuration of $36 \mathrm{~km}$ horizontal resolution and 18 vertical levels over the domain of $5^{\circ} \mathrm{S}$ to $27^{\circ} \mathrm{N}, 85$ to $130^{\circ} \mathrm{E}$.

RegCM3 data were spatially interpolated from the model grid to the 58 locations using distanceweighted averaging. That means the value at each station is averaged from all RegCM3 grid boxes within a radius of $20 \mathrm{~km}$ around the station, where the grid box nearest to a station contributes more than those further away.

\subsection{Indices of climate extremes}

This study focuses on the extreme climatic events of hot summer days, cold winter nights and heavy rainfall days. These extremes are defined based on the 95th and 5th percentiles of daily maximum temperature $\left(T_{\max }\right)$ and daily minimum temperature 

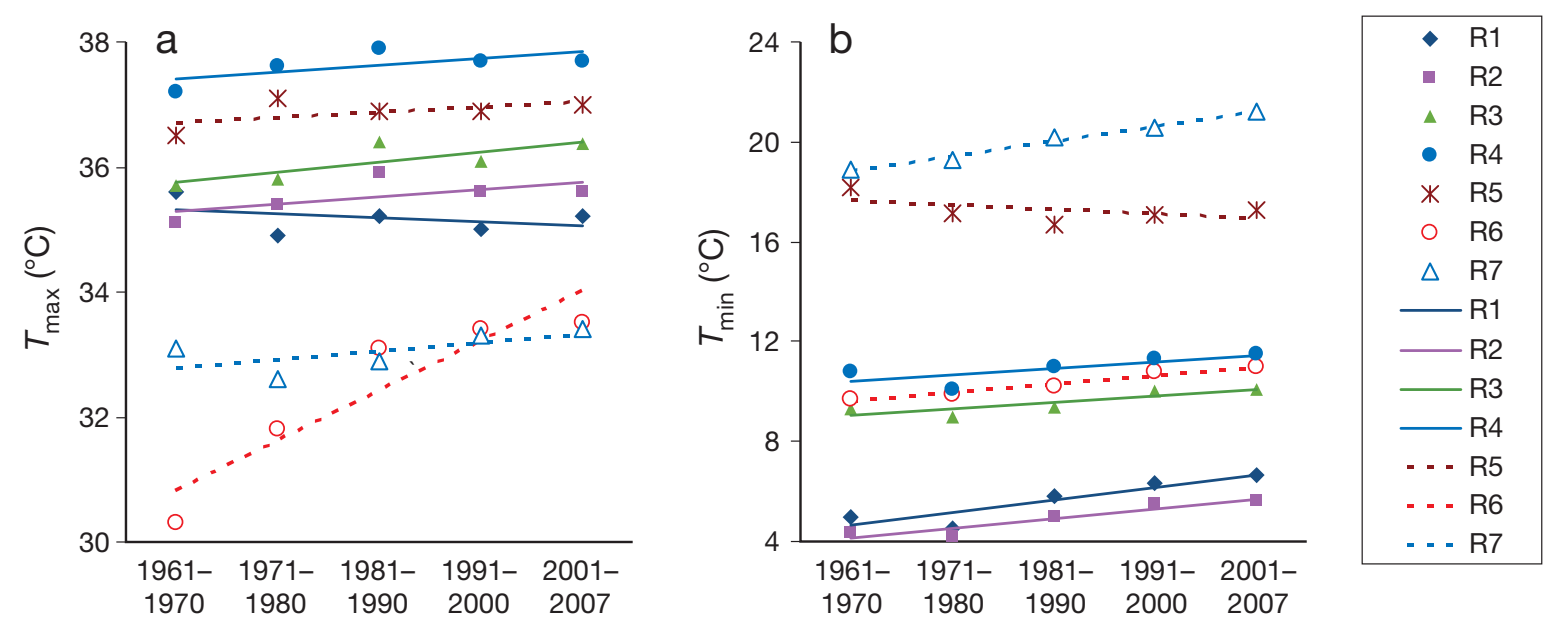

Fig. 2. (a) 95th percentile threshold $\left({ }^{\circ} \mathrm{C}\right)$ of maximum temperature $\left(T_{\max }\right)$ in summer $(\mathrm{JJA})$ and (b) 5 th percentile threshold $\left({ }^{\circ} \mathrm{C}\right)$ of minimum temperature $\left(T_{\min }\right)$ in winter $(\mathrm{DJF})$ and their linear trend lines

$\left(T_{\min }\right)$, respectively, and daily total rainfall $(R)$ of wet days with a rainfall $>1 \mathrm{~mm}$ (Endo et al. 2009). For $T_{\max }, T_{\min }$ and $R$, all daily data in the considered time period of all stations in each sub-region were ordered and then the 5th and 95th percentiles were calculated. Thus, all available daily data within a subregion are considered as separate data points where an extreme event may occur. Table 2 shows the criteria of extreme climate events.

\section{RESULTS AND DISCUSSION}

\subsection{Extremes during 1961-2007}

The daily historical observed data of $T_{\min }, T_{\max }$ and $R$ from 1961 to 2007 were analyzed to detect extreme events and their decade-by-decade trends. For each of the periods 1961-1970, 1971-1980, 1981-1990, 1991-2000 and 2001-2007, $T_{\max 95}$ in summer, $T_{\min 5}$ in winter and $R_{95}$ in the rainy season are shown for the 7 sub-regions in Figs. $2 \&$ 5. In general, $T_{\max 95}$ in the summer and $T_{\min 5}$ in the winter both show a gradual increase.

Table 2. Criteria of extreme climate events. $T_{\max }$ : maximum temperature; $T_{\max 95}: 95$ th percentile of $T_{\max } T_{\min }:$ minimum temperature; $T_{\min 5}: 5$ th percentile of $T_{\min } R$ : daily total rainfall; $R_{95}$ : 95th percentile of $R$

\begin{tabular}{|cc|}
\hline Extremes & Criteria \\
\hline Hot days & $T_{\max }>T_{\max 95}$ \\
Cold nights & $T_{\min }<T_{\min 5}$ \\
$R>R_{95}$ \\
Heavy rainfall days & $R$ \\
\hline
\end{tabular}

The decrease of $T_{\min 5}$ over sub-region R5 from 1961 to 1990 seems to be a consequence of the shift of the polar cold air in the prevailing active season of the northeast winter monsoon. Basically, sub-region R5 is not affected by cold air because of the blocking of cold air by BachMa ridge at $16^{\circ} \mathrm{N}$; this is revealed by the climatic position of the $1015 \mathrm{hPa}$ isobar of sea level pressure crossing sub-region R5 around $16^{\circ} \mathrm{N}$. As shown in Fig. 3, before 1970, this isobar was located in the north of its climatic position, but it moved south after 1980. However, the effect of some cold surges cannot overcome global warming, so $T_{\min 5}$ of R5 increases slightly from 1990 to the present

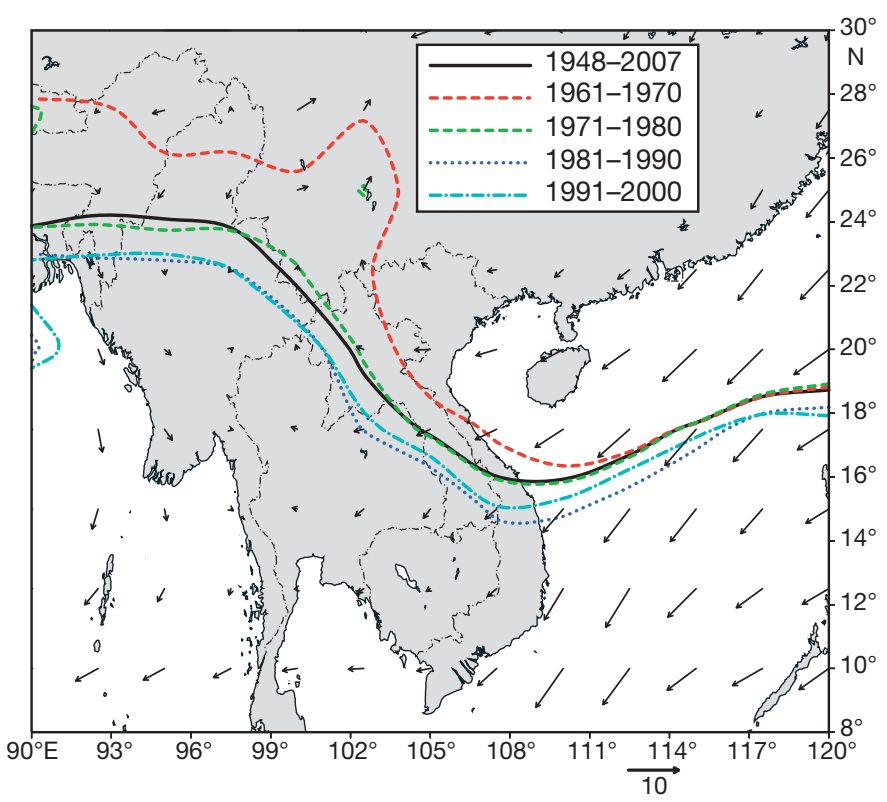

Fig. 3. Isobar of $1015 \mathrm{hPa}$ sea level pressure for different time periods (lines) and the winter (DJF) average surface wind (vectors) during 1948-2007; data from Kalnay et al. (1996) 

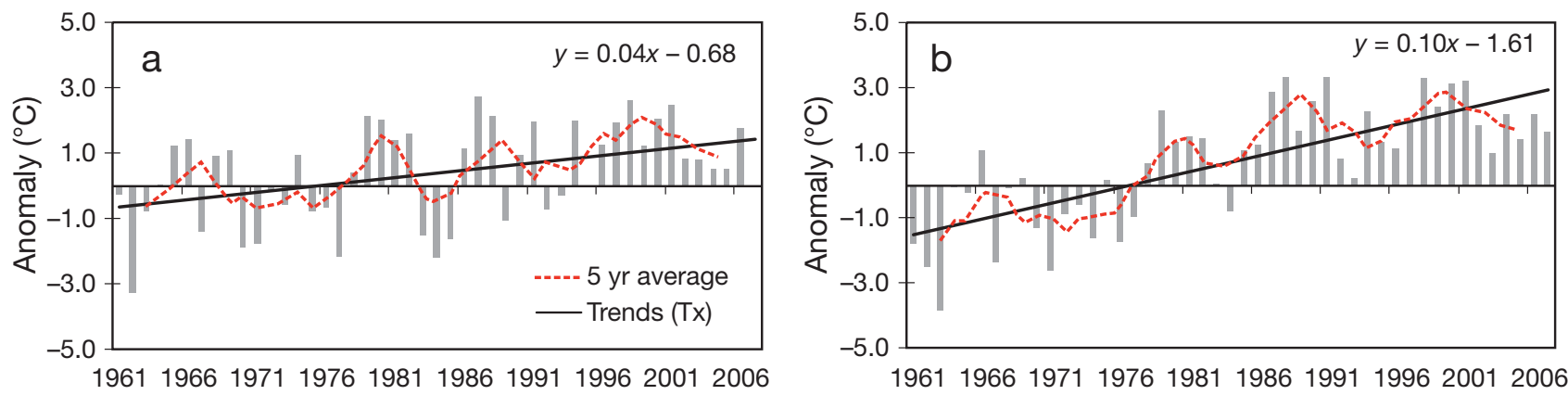

Fig. 4. Trends of monthly near surface air (a) maximum temperature ( $\left.T_{\max }\right)$ in July and (b) minimum temperature ( $\left.T_{\min }\right)$ in January during 1961-2007 over sub-regions R1-R5 in Vietnam

day. Fig. 4 shows that $T_{\max }$ in summer increases by $0.4^{\circ} \mathrm{C}$ decade $^{-1}$ over R1-R5, which is slower than the increase of $T_{\min }$ in winter. Thus, the southward shift of the $1015 \mathrm{hPa}$ isobar partly explains the different behavior of $T_{\max 95}$ and $T_{\min 5}$ (Fig. 2). Significance of the trends in Fig. 3 was determined through Student's $t$-test, the coefficient $A_{1}$ of the trend line ( $y=$ $\left.A_{0}+A_{1} x\right)$ was assessed by Fisher's $F$-test, and the nonparametric Mann-Kendall test has been used to evaluate the trend in the time series of climatologic data.

Each sub-region has its own 95th and 5th percentile values. Hence, the use of a unique threshold for each sub-region to define temperature extremes is important (Ghosh et al. 2009).

$R_{95}$ in the wet season characterizes the threshold for the occurrence of heavy rainfall. Except for the rapid increase over $\mathrm{R} 5$, the $R_{95}$ value is maintained or increases slightly over the different sub-regions (Fig. 5). Here, from the 1990s to 2007, R2 and R4 show a stronger increasing trend, which may be partially related to natural decadal variability.

Over the sub-regions R1-R3 and R6-R7, the correlation coefficient between the first mode of principal

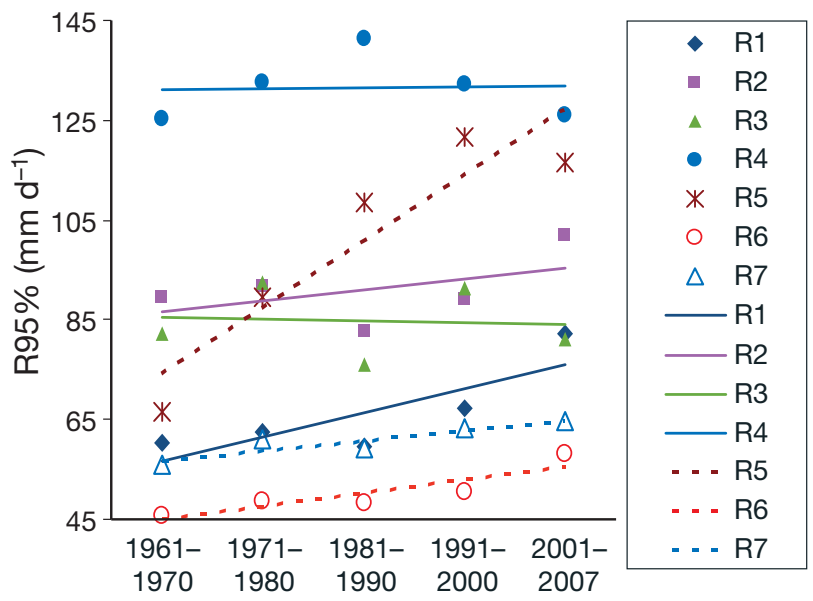

Fig. 5. 95th percentile threshold of daily precipitation $\left(\mathrm{mm} \mathrm{d}^{-1}\right)$ in wet months $\left(R_{95}\right)$ for all sub-regions component analysis (PCA) of surface temperature ( $T_{\mathrm{S}}$ from ERA40 data) and sea surface temperature (SST; from NCEP data) over Southeast Asia with the monthly maximum amount of rainfall is approximately 0.8 (not shown). Hence, heavy rainfall over those sub-regions is associated with global warming, which is consistent with previous studies (Trenberth et al. 2003, Liu et al. 2009). Nevertheless, Endo et al. (2009) showed for a similar time period (1950s to 2007 ) that the annual total precipitation and average precipitation from wet days decreased over northern Vietnam and increased over southern Vietnam. A similar result was also obtained from our research on the historical data from 1961-2007. This implies that global warming increases the whole rainfall distribution over southern Vietnam, whereas over northern Vietnam only the heavy rainfall is increased. The latter means that over northern Vietnam, although heavy precipitation events increase because of global warming, the light and mild rainfall events decrease at the same time, so that consequently the total rainfall decreases. This has lead to a more severe climate in northern Vietnam, as both flood and drought events happen more often.

The correlation coefficient between the monthly maximum amount of rainfall and temperature over sub-regions R4 and R5 is lower, but its absolute value in the case of evaporation and relative humidity is higher than that of other sub-regions (not shown). This may be a result of the fact that heavy rainfall in the coastal provinces of these 2 sub-regions is often related to the seasonal migration of the Inter-tropical Convergence Zone and typhoons over the northwest Pacific and South China Sea. With global warming, the warmer sea surface temperature (SST) increase typhoon probability and, hence, the intensification of heavy rainfall. In order to investigate whether this is the case, the NetTC index was considered. This index is based on the NTC index defined by Gray et al. (1994) and characterizes the total number of tropi- 
cal cyclones over the South China Sea $\left(100-120^{\circ}\right.$ E, $0-23^{\circ} \mathrm{N}$ ), the number of strong typhoons at several different strengths and the number of storm days per year:

$$
\begin{gathered}
\text { NetTC }=(\% \text { TC }+\% \text { TC8 }-9+\% \text { TC } 10-11+ \\
\% \text { TC12up }+\% \text { TCDay }) / 5
\end{gathered}
$$

Here, \% TC is the ratio of annual number of tropical cyclones with a maximum wind speed of 10.8$17.2 \mathrm{~m} \mathrm{~s}^{-1}$ at the storm core, divided by the total number of tropical cyclones during 1981-2007. \% TC8-9, \% TC10-11 and \% TC12up are defined analogously to \% TC considering tropical cyclones with a maximum wind speed of 17.2-24.4, 24.5-32.6 and $>32.7 \mathrm{~m} \mathrm{~s}^{-1}$ at the storm core, respectively. \% TCDay is the ratio of the annual number of tropical cyclone days to the total number of days of tropical cyclones during 1981-2007.

Data on tropical cyclones were collected from the website http://weather.unisys.com. To investigate the relation of typhoons with global warming, the NetTC index was correlated with global SST (Fig. 6).
We restricted the analysis to 1981-2007, as NCEP SST data were only available to us from 1981 onwards. The highest correlation of the NetTC index and SST occurs over 4 regions: Region $1\left(5-25^{\circ} \mathrm{N}\right.$, $\left.150-165^{\circ} \mathrm{E}\right)$; Region $2\left(8^{\circ} \mathrm{S}-4^{\circ} \mathrm{N}, 80-90^{\circ} \mathrm{W}\right)$; Region $3\left(0-30^{\circ} \mathrm{N}, 100-180^{\circ} \mathrm{E}\right)$; and Region $4\left(5^{\circ} \mathrm{S}-5^{\circ} \mathrm{N}, 40-\right.$ $\left.50^{\circ} \mathrm{E}\right)$. The general correlation pattern corresponds to the large changes in SST between the 2 periods 1981-1990 and 1991-2000 (Fig. 7).

Fig. 8 shows that the number of typhoons has the same SST dependence as the NetTC index over all 4 regions. Tropical cyclones in general and intense typhoons in particular increase over Regions 1 and 3 when SST increases. In contrast, they decrease if SST increases over Regions 2 and 4. As SST tends to increase over Regions 1 and 3 and decreases over Regions 2 and 4, the number of tropical cyclones tends to increase over the whole South China Sea.

The 2 sub-regions R4 and R5 are mostly affected by typhoons. However, the number of typhoon seems to have increased over R5 and decreased over R4 in the last 2 decades. In order to clarify this, tropical cyclone

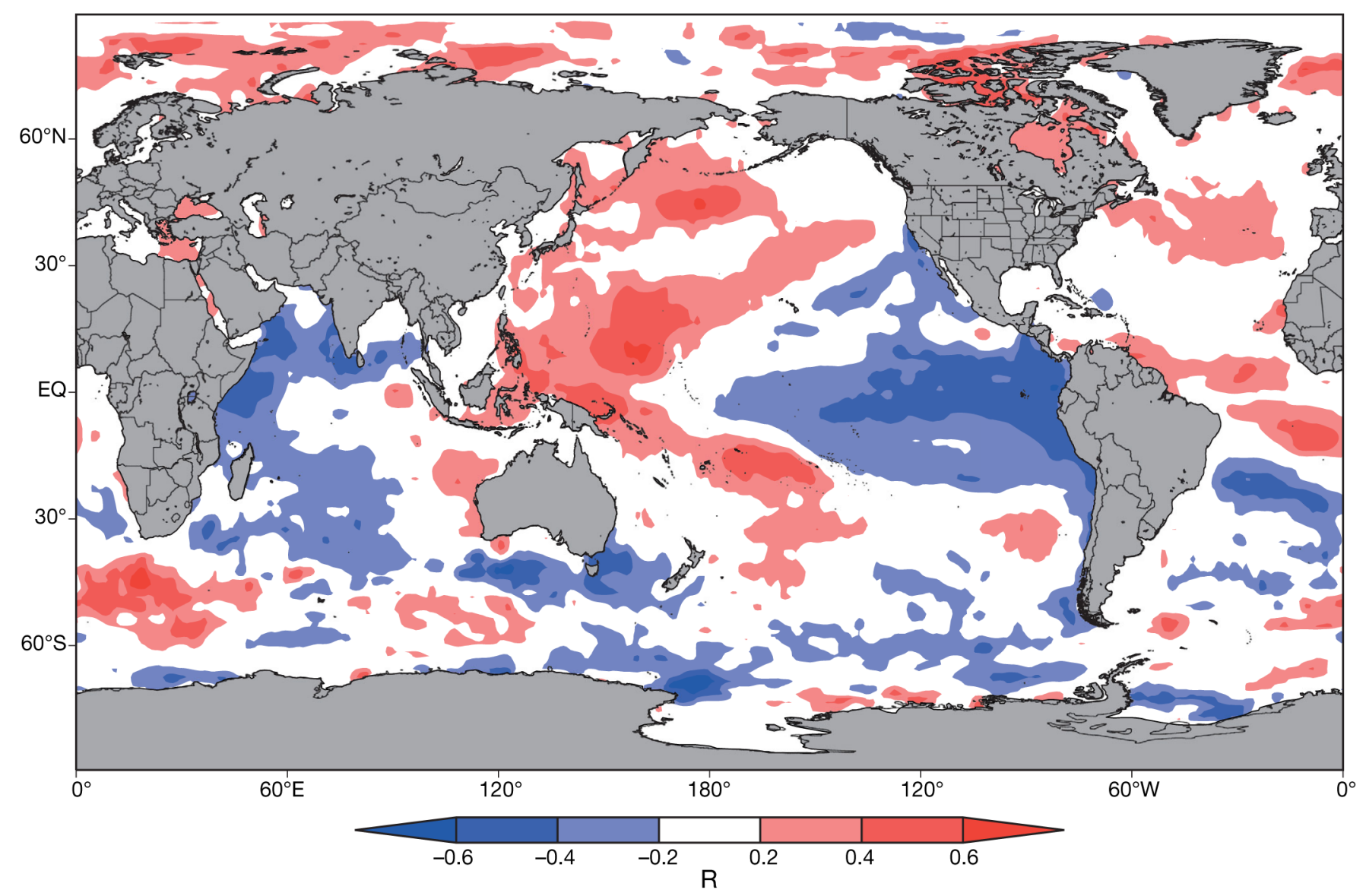

Fig. 6. Correlation coefficient of NetTC (the total number of tropical cyclones over the South China Sea, the number of strong typhoons at several different strengths and the number of storm days per year) with sea surface temperature during 1981-2000 


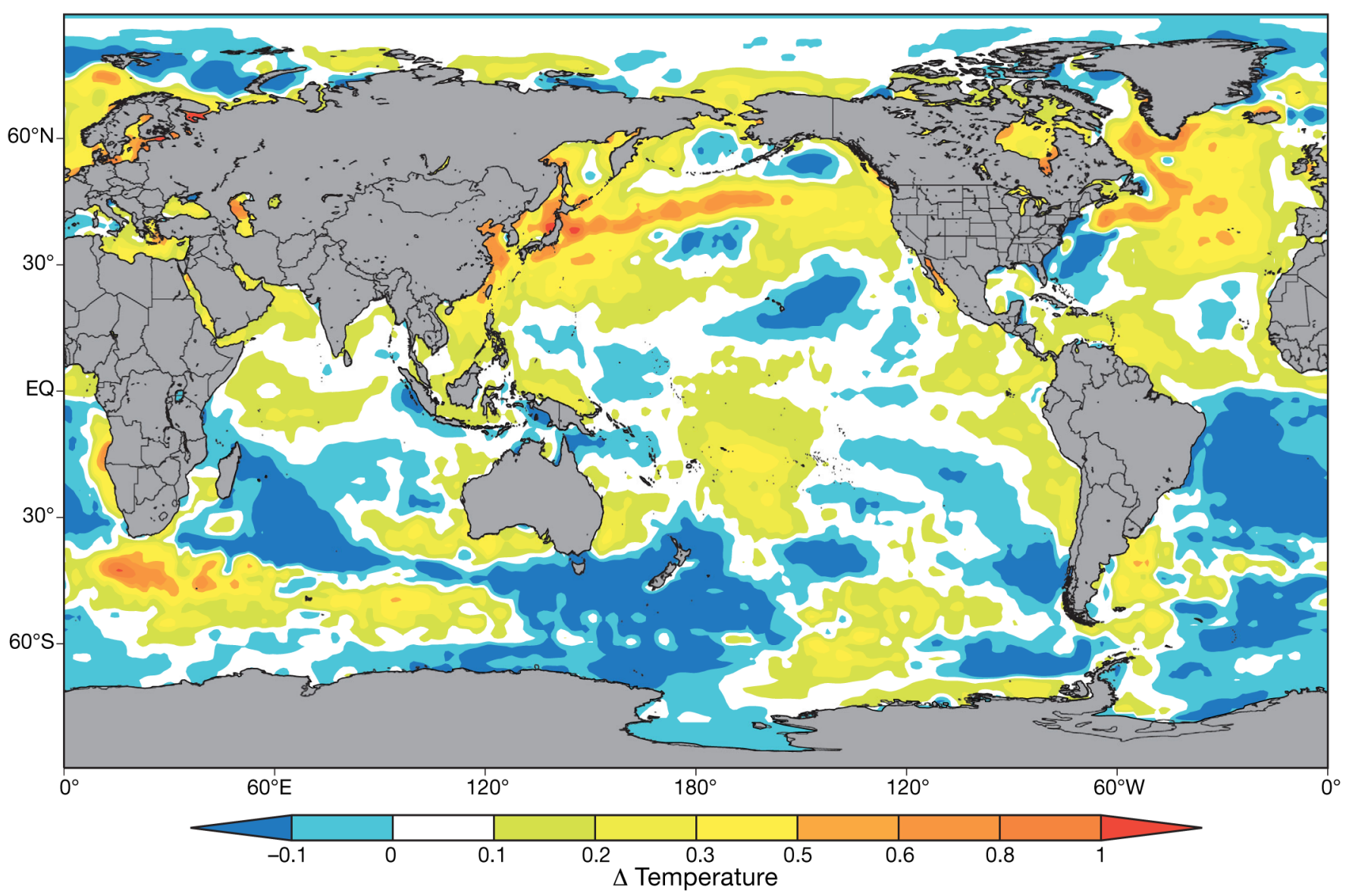

Fig. 7. Temperature difference $\left({ }^{\circ} \mathrm{C}\right)$ between $1991-2000$ and 1981-1990

data during 1945-2007 were collected (from http:// weather.unisys.com) and extracted for tropical cyclones that influenced Vietnam. The difference in strike probability of tropical cyclones during 19912007 from 1945-1990 was calculated for both R4 and R5 (Fig. 9). The annual averaged probability difference is $-5 \%$ for $\mathrm{R} 4$ and $+4.4 \%$ for R5. Thus, the change in tropical cyclones may have led to the decrease of $R_{95}$ over R4 and its increase over R5.

In summary, the precipitation extreme threshold also increases for most sub-regions, except over R3 and R4, with the fastest rate found for R5, which may be related to the increasing number of tropical cyclones over the South China Sea in the last 2 decades. Similar to the temperature cases, the precipitation extreme thresholds are different for individual subregion with the greatest value over R1 and the lowest value over R6. We found the same situation in the case of the baseline simulation of RegCM3. Hence, in the next section the specific thresholds for each subregion are calculated for the baseline simulation and then applied to the climate projections.

\subsection{Extremes during 2001-2050}

In order to detect the extreme events from the climate projections, we determined the temperature and precipitation extreme thresholds from the baseline simulation of RegCM3 using a similar method as for the observations (see Section 3.2), and then we applied these thresholds to the climate change projections of RegCM3 based on the A1B and A2 scenarios for the years 2001-2050. Finally, the difference in the seasonal number of heavy rainfall days, hot days and cold nights between the scenarios to the baseline for 7 sub-regions was calculated.

First, the performance of RegCM3 was verified by comparing the baseline simulation with the observation data for 1980-1999. RegCM3 was set up with a finer resolution than in Phan et al. (2009). Because of the higher resolution, the cold bias of monthly $2 \mathrm{~m}$ temperature was reduced and the model reproduced heavy rainfall areas much better than the previous study (not shown), but the model still has systematic cold biases in $T_{\max }$ and $T_{\min }$ (e.g. Fig. 10, Table 3), 


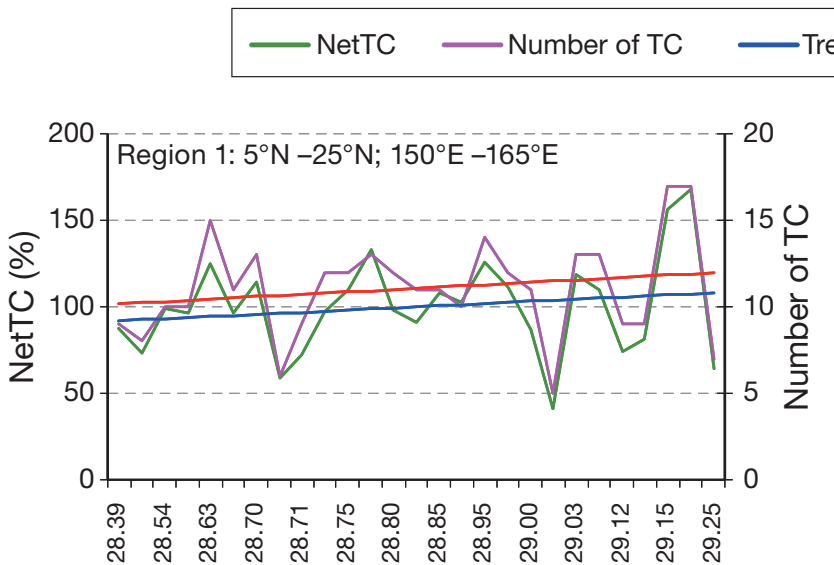

Trend of NetTC Trend of Number of TC

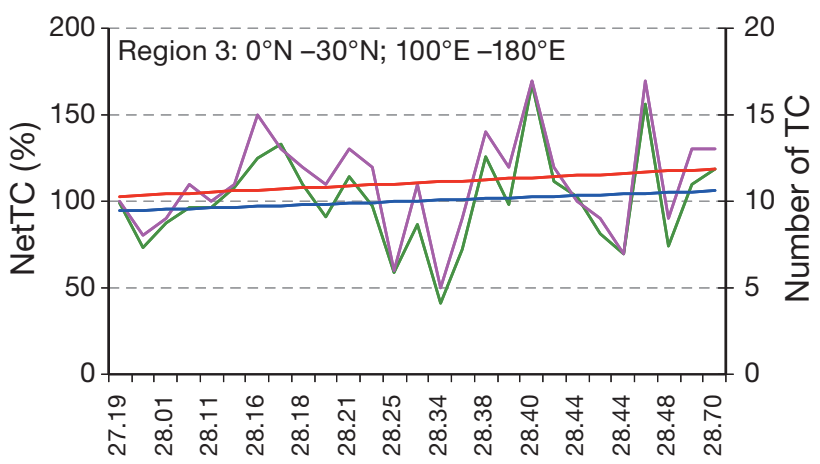

SST $\left({ }^{\circ} \mathrm{C}\right)$
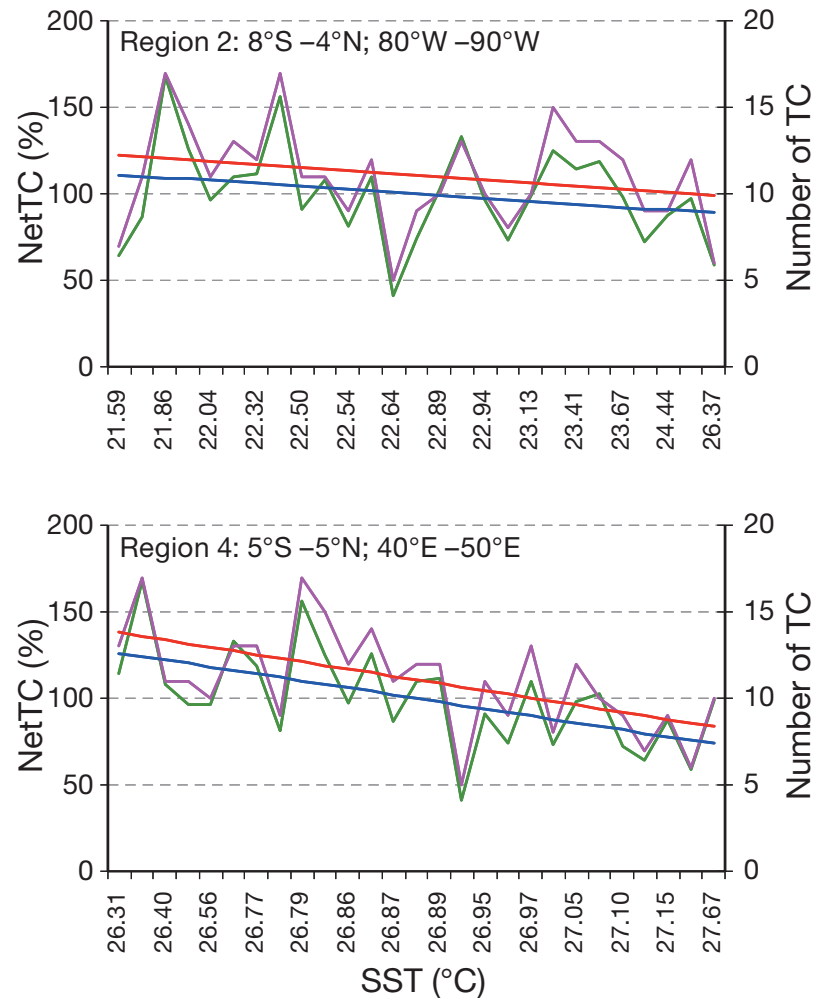

Fig. 8. Number of tropical cyclones (TC) over the South China Sea and NetTC index against sea surface temperature (SST)

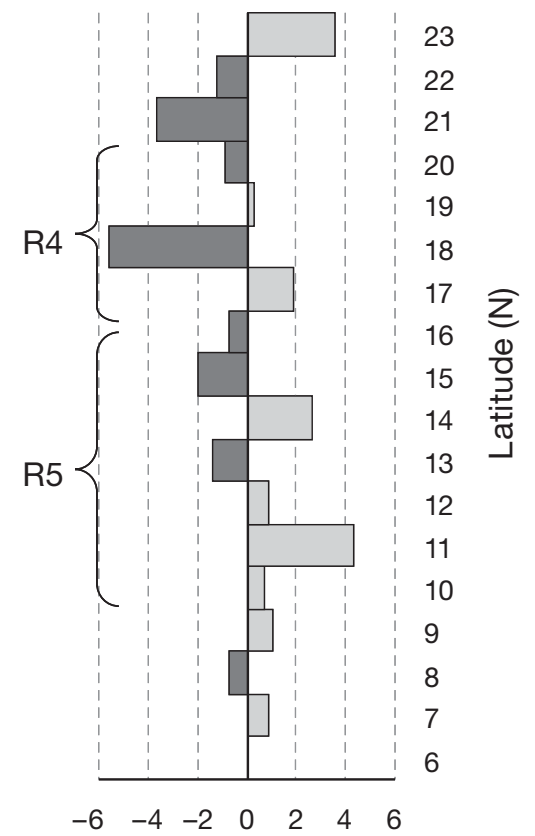

Probability difference (\%)

Fig. 9. The difference in strike probability of tropical cyclones between 1991-2007 and 1945-1990 over the South China Sea and dry biases in wet day rainfall. Phan et al. (2009) and Ho (2008) used RegCM3 forced by ERA40 data to simulate the climate over Vietnam and showed that RegCM3 systematically underestimates the near surface temperature by several degrees compared with station observations. One of the major reasons is that topography in RegCM3 is different from reality. Thus, in the present study, the temperature field of RegCM3 was also spatially interpolated onto the 58 observation station locations and adjusted by the height displacement using the moist adiabatic lapse rate $\left(\gamma=-0.65^{\circ} \mathrm{C} / 100 \mathrm{~m}\right)$ for mountainous stations. This step is necessary, especially for $T_{\min }$ as the value after height correction significantly affects the 5th percentile.

Despite the general cold bias compared with observations, RegCM3 captured the shape of the probability distribution of the temperature over all subregions, as shown for R2 and R4 in Fig. 10. The distributions of $T_{\min }$ and $T_{\max }$ in the scenario projections resemble that of the baseline simulation, but the peaks are shifted towards higher values.

For precipitation, RegCM3 forced by CCSM3 overestimates the monthly rainfall in the highest rainfall 
[R2]

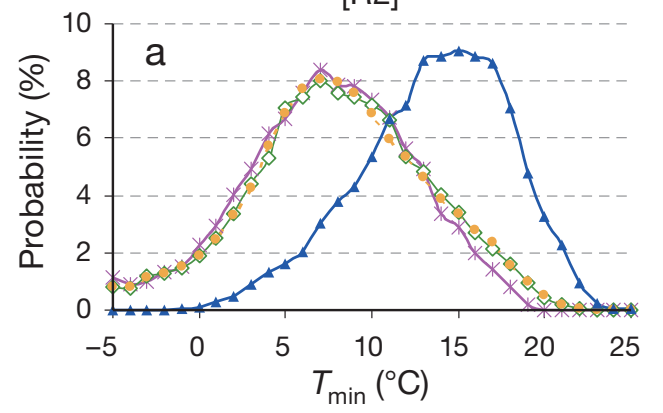

[R4]

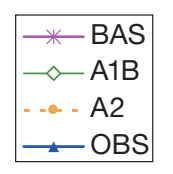

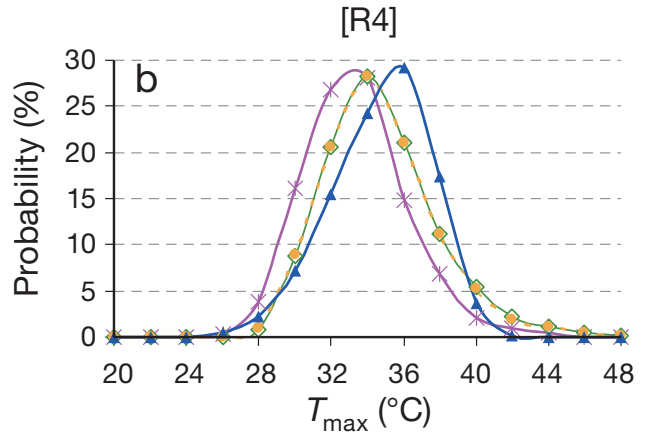

Fig. 10. Probability distribution of (a) minimum temperature ( $\left.T_{\min }\right)$ over sub-region R2 and (b) maximum temperature ( $\left.T_{\max }\right)$ over sub-region R4 for the baseline simulation (BAS), scenario projections A1B and A2, and observation data (OBS)

period (Table 3), while in the study of Phan et al. (2009), the monthly precipitation of RegCM3 forced by ERA40 was underestimated in the rainy season over R1-R3 and R7, overestimated over R4 and R5, and slightly underestimated over R6. However, the wet day rainfall (Table 3) is similar to that of Phan et al. (2009) except for R6, where this is now largely overestimated. Although RegCM3 has a wet day rainfall dry bias over 4 of the 7 sub-regions, including R1-

Table 3. The mean bias of daily maximum and minimum temperature ( $T_{\max }$ and $T_{\min }$, respectively) as well as mean wet day precipitation $(R)$ and mean monthly precipitation in the highest rainfall period for the baseline simulation compared with the observations

\begin{tabular}{|lcccc|}
\hline Sub-region & $\begin{array}{c}T_{\min } \\
\left({ }^{\circ} \mathrm{C}\right)\end{array}$ & $\begin{array}{c}T_{\max } \\
\left({ }^{\circ} \mathrm{C}\right)\end{array}$ & $\begin{array}{c}R \\
\left(\mathrm{~mm} \mathrm{~d}^{-1}\right)\end{array}$ & $\begin{array}{c}\text { Monthly rainfall } \\
\left(\mathrm{mm} \mathrm{d}^{-1}\right)\end{array}$ \\
\hline R1 & -6.21 & 3.22 & -0.40 & 8.53 \\
R2 & -6.08 & 0.77 & -1.63 & 9.41 \\
R3 & -5.12 & -0.66 & -14.04 & 0.84 \\
R4 & -3.59 & -1.36 & 0.23 & 16.47 \\
R5 & -1.40 & -1.37 & 30.29 & 39.06 \\
R6 & -0.44 & 1.75 & 28.33 & 32.26 \\
R7 & -0.66 & -0.53 & -5.92 & 1.85 \\
\hline
\end{tabular}

R3 and R7, the precipitation extremes are overestimated in the baseline simulation over almost all subregions except over R4 and R7 (see Fig. 11, Table 4). Table 4 shows the mean bias of the number of monthly cold nights, hot days and heavy rainfall days for the baseline simulation. Here, extreme events of observed or simulated data are defined based on their respective percentile thresholds. In Table 4, the small cold bias of RegCM3 is also shown for all subregions except over R5 and R7 in the case of cold nights and R3 and R6 in the case of hot days.

In spite of some general biases, RegCM3 repro-

Table 4. Mean bias of the number of cold nights, hot days and heavy rainfall days per month for the baseline simulation compared with the observations

\begin{tabular}{|lccc|}
\hline Sub-region & Cold nights & Hot days & Heavy rainfall days \\
\hline R1 & -0.16 & -0.08 & 0.06 \\
R2 & -0.06 & -0.45 & 0.38 \\
R3 & -0.04 & 0.05 & 0.19 \\
R4 & -0.01 & -0.38 & -0.29 \\
R5 & 0.10 & -0.27 & 0.75 \\
R6 & -0.35 & 0.28 & 0.13 \\
R7 & 0.12 & -0.18 & -0.07 \\
\hline
\end{tabular}
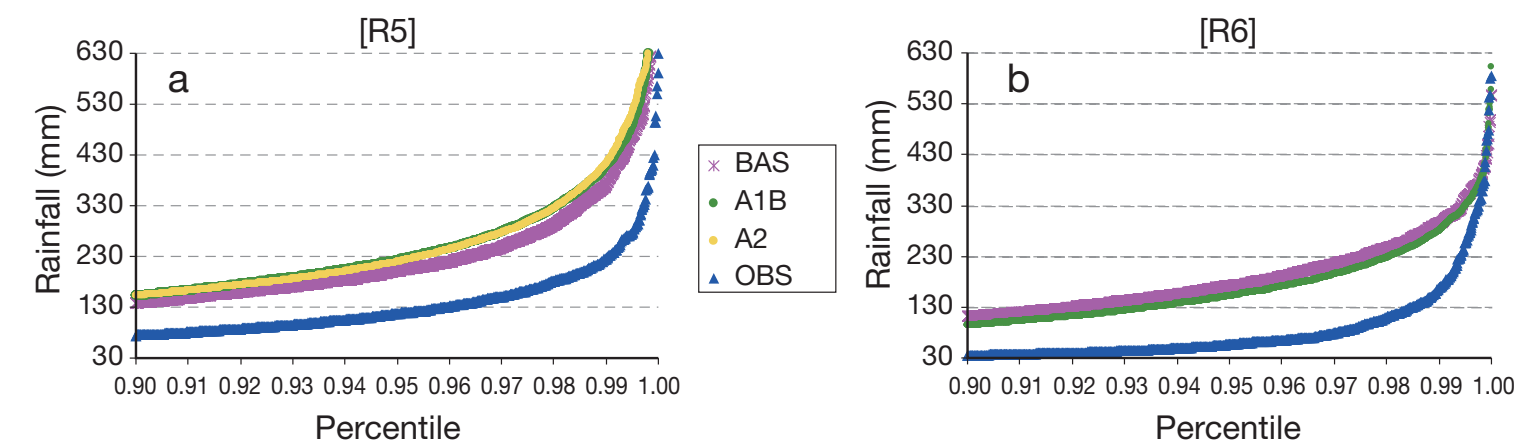

Fig. 11. Daily total rainfall in the 10 highest percentiles of the baseline simulation (BAS), scenario projections A1B and A2, and observation data (OBS) over sub-regions (a) R5 and (b) R6; in (b), data for A2 are practically identical with A1B 


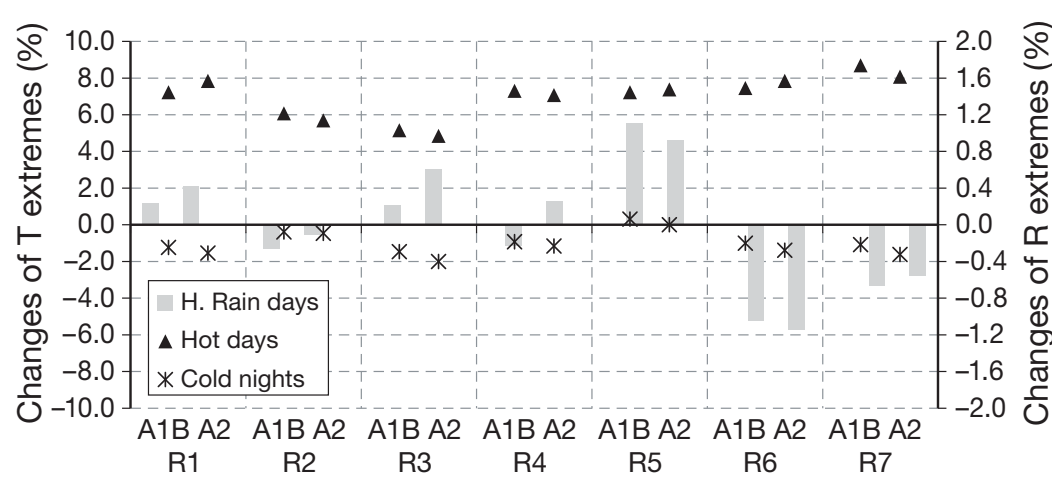

Fig. 12. Projected changes in the seasonal number of heavy rainfall days, hot days and cold nights over the 7 sub-regions for the A1B (left entries) and A2 (right entries) scenarios

duces the shape of the temperature and rainfall probability distributions and simulates them steadily in the scenarios (e.g. Fig. 11). Moreover, the circulation is captured well by RegCM3 in the present baseline simulation (not shown) as well as in the previous simulation by Phan et al. (2009). This is a reasonable foundation for calculating the difference in extreme events between the scenarios and the baseline simulations to address the projected future changes (Fig. 12).

The number of summer hot days increases over every sub-region by $5-9 \%$ compared with the baseline period. In contrast, the number of cold nights in the 3 major winter months is $1-2 \%$ less than that of the baseline period, except in R5. The special character of sub-region R5 should be considered thoroughly in future studies, as this sub-region is one of 2 subregions that tend to change its rainfall more significantly than the others.

Heavy rainfall events tend to be stable or decrease for almost all sub-regions with the greatest decline

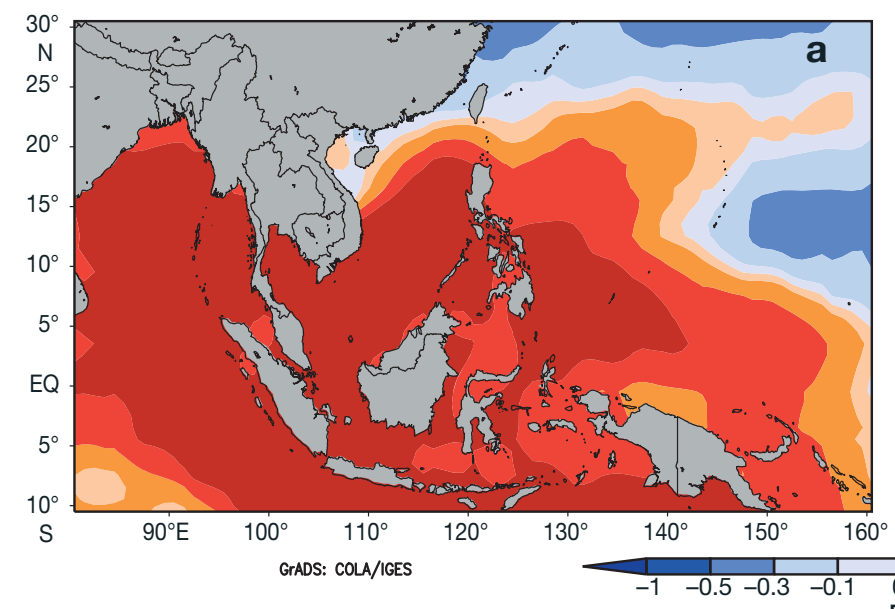
precipitation extremes, $\mathrm{A} 1 \mathrm{~B}$ and $\mathrm{A} 2$ usually projected the same trends over all sub-regions except R2 and R4. The remarkable changes in the number of heavy rainfall days usually happen a decade later in the A2 simulation than for A1B (not shown), which is likely caused by the significantly different simulation of sea level pressure and circulation fields in A1B. Although there is a similar influence on temperature and precipitation extreme events between the 2 scenarios, A2 likely has stronger impacts on cold nights and heavy rainfall days.

The increasing trend of heavy rainfall over R5 in the next decades seems to be associated with the intensification of the number or the intensity of severe tropical cyclones over the South China Sea and the Pacific Ocean due to global warming. The decline of heavy rainfall over R6 can be partly explained by the relationship with SST over the South China Sea (Fig. 13), i.e. with global warming, increases in SST over this area may lead to the increase of hot days and the decrease of heavy rain-

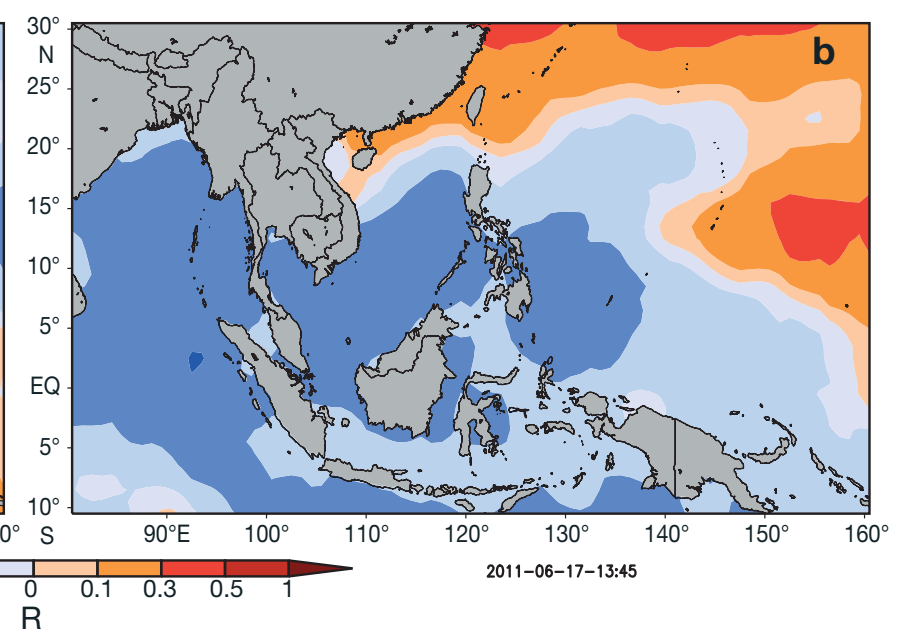

Fig. 13. Correlation coefficients between (a) maximum temperature $\left(T_{\max } i^{\circ} \mathrm{C}\right)$ of sub-region R6 and sea surface temperature $\left(\mathrm{SST}_{i}{ }^{\circ} \mathrm{C}\right)$ and $(\mathrm{b})$ rainfall $\left(\mathrm{mm} \mathrm{d}^{-1}\right)$ of sub-region R6 and SST in the summer months in 1982-2001 


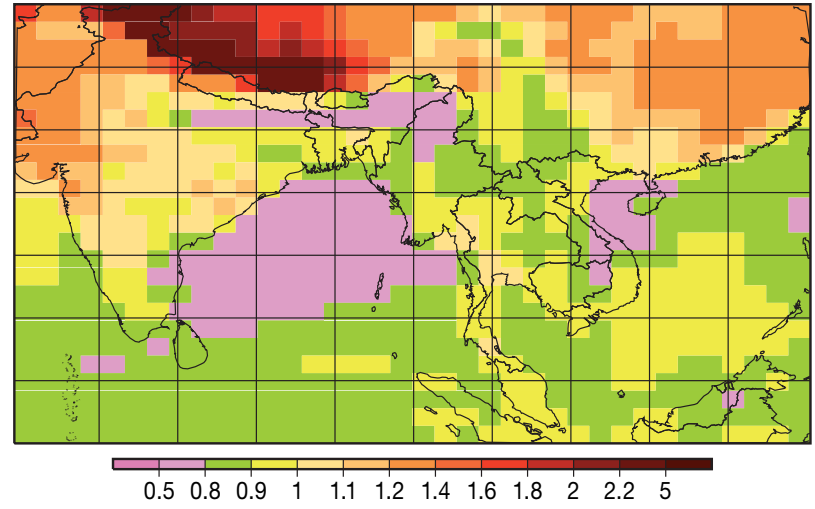

Fig. 14. Change in CCSM3 surface temperature $\left({ }^{\circ} \mathrm{C}\right)$ between the A1B scenario period 2001-2050 and the baseline period 1980-1999

fall days over R6. The correlation between monthly rainfall of sub-region R6 and SST in the summer months of the baseline simulation is similar to that in the historical data (not shown). Here, the negative correlation area is extended over the Bay of Tonkin. The change in CCSM3 surface temperature between the A1B scenario period 2001-2050 and the baseline period 1980-1999 is shown in Fig. 14. SST increases over the whole domain, perhaps leading to the descent of precipitation extremes over R6 as well as over R7. Basically, the wet season rainfall over R6 and R7 is mainly generated by the Asian summer monsoon (Pham \& Phan 1993). In the driving wind fields of CCSM3, a reduction of the southwesterly monsoon flow to R6 and R7 occurs in the scenario period, which may contribute to the decrease in heavy rainfall owing to a reduced moisture transport (not shown).

A further contribution to the decreased precipitation may be enhanced monsoon break conditions, a detailed analysis of which is beyond the scope of the present study. However, Joseph \& Srinivasan (1999) suggested that a Rossby wave is induced by the anomalous heat sources in the Bay of Bengal and adjoining regions in May. Krishnan et al. (2000) pointed out that a major intensification of the convectively stable anomalies over the Bay of Bengal, triggered by the rapid northwest propagating Rossby waves, occurs prior to the commencement of a monsoon break. And an Indian monsoon break also contributes to the decrease of precipitation over the Indochina Peninsula.

When considering the first decade of the 21th century, generally there seems to be some consistency in the trends of precipitation extremes over Vietnam between the $\mathrm{A} 1 \mathrm{~B}$ and $\mathrm{A} 2$ projections and observa- tions as presented in the first part of this study (Fig. 5). But the wetter trend over R1 likely persists in the A1B projection, similar to the 2001-2007 mean from the observational data, whereas in the A2 scenario, a drying trend is projected (not shown). Ensemble runs with state-of-the-art regional climate models such as REMO (Max Planck Institute for Meteorology) and MM5-CL (climate mode of the Mesoscale Model version 5) are planned to generate more robust conclusions.

\section{CONCLUSIONS}

Extreme events and their decade-by-decade variations are varied over the 7 sub-regions because of their different local climate characters. The subregion R6 has the fastest increase in maximum temperature in the summer, whereas R5 stands out because of its decreasing trend in minimum temperature in the winter. The 3 sub-regions R5, R6 and R7 in southern Vietnam exhibit a dramatic increase in heavy rainfall events in their wet seasons. For the years 2001-2050, based on the IPCC SRES A1B and A2 scenarios, the number of hot days will increase and the number of cold nights will decrease as a consequence of global warming. Heavy rainfall events tend to remain unchanged or to decrease for all subregions except $\mathrm{R} 5$. The continuously increasing rainfall over R5 is related to the tropical cyclone numbers and strength over the west Pacific Ocean and South China Sea regions, which are intensifying because of the increased SST in the projections. The remarkably opposite projected change in precipitation extremes over R6 seems to be linked to changes in the southwesterly flow from the Bay of Bengal and an associated reduced moisture transport into the region. As the heavy rainfall trends over Vietnam are consistent between model predictions and observations for the first decade of the 21st century, this indicates that the RegCM3 projections are reasonable. This study is the initial step of an ensemble run using several other regional climate models to generate more robust conclusions.

Acknowledgements. This study has been supported by the Vietnamese National Funded Project 'The Impacts of Global Climate Change on Extreme Climate Events over Vietnam, Predictability and Adaptation Strategic Solutions' coded KC.08.29/06-10. The IPCC DDC AR4 NCAR-CCSM3 data were obtained from the Earth System Grid at the National Center for Atmospheric Research (www.earthsystemgrid. org) and the World Data Center for Climate CERA database (http://cera-www.dkrz.de/CERA/). We thank Dr. Stefan 
Hagemann from the Max Planck Institute for Meteorology (Germany) and Dr. John McGregor from Commonwealth Scientific and Industrial Research Organisation (Australia) for their support with English writing and scientific discussion. We thank the anonymous reviewers for their very useful suggestions and comments.

\section{LITERATURE CITED}

Alexander LV, Zhang X, Peterson TC, Caesar J and others (2006) Global observed changes in daily climate extremes of temperature and precipitation. J Geophys Res 111: DO5109

Anthes R, Hsie E, Kuo YH (1987) Description of the Penn State/NCAR Mesoscale Model Version 4 (MM4). Tech Rep NCAR/TN-282, National Center for Atmospheric Research, Boulder, CO

Bell JL, Sloan LC, Snyder MA (2004) Regional changes in extreme climatic events: a future climate scenario. J Clim 17:81-87

Dickinson RE, Henderson-Sellers A, Kennedy PJ (1993) Biosphere-Atmosphere Transfer Scheme (BATS) version 1e as coupled to the NCAR community climate model. National Center for Atmospheric Research, Boulder, CO

Diffenbaugh NS, Ashfaq M (2010) Intensification of hot extremes in the United States. Geophys Res Lett 37: L15701. doi:10.1029/2010GL043888

Endo N, Matsumoto J, Lwin T (2009) Trends in precipitation extremes over Southeast Asia. Sci Online Lett Atmos 5: 168-171

Francis D, Hengeveld D (1998) Extreme weather and climate change. Canada Minister of Supply and Services, Climate and Water Productions Division, Ottawa

Ghosh S, Luniya V, Gupta A (2009) Trend analysis of Indian summer monsoon rainfall at different spatial scales. Atmos Sci Lett 10:285-290 doi:10.1002/asl.235

Giorgi F (2006) Regional climate modeling: status and perspectives. J Phys IV France 139:101-118

Giorgi F, Whetton PH, Jones RG, Christensen JH and others (2001) Emerging patterns of simulated regional climatic changes for the 21st century due to anthropogenic forcings. Geophys Res Lett 28:3317-3320

Gray WM, Landsea CW, Mielke PW Jr, Berry KJ (1994) Predicting Atlantic basin seasonal tropical cyclone activity by 1 June. Weather Forecast 9:103-115

Groisman PY, Karl TR, Easterling DR, Knight RW and others (1999) Changes in the probability of heavy precipitation: important indicators of climatic change. Clim Change 42: $243-283$

Halenka T, Kalvová J, Chládová Z, Demeterová A, Zemánková K, Belda M (2006) On the capability of RegCM to capture extremes in long term regional climate simulation - comparison with the observations for Czech Republic. Theor Appl Climatol 86:125-145

> Hegerl GC, Karl TR, Allen M, Bindoff NL and others (2006) Climate change detection and attribution: beyond mean temperature signals. J Clim 19:5058-5077

Ho TMH (2008) Using the dynamic-statistical method to assess the seasonal climate simulation capability of Vietnam. PhD dissertation, Hanoi University of Sciences

Holtslag AAM, Bruijn EIF, Pan HL (1990) A high resolution air mass transformation model for short-range weather forecasting. Mon Weather Rev 118:1561-1575

Im ES, Kim MH, Kwon WT, Cocke S (2007a) Projected change in mean and extreme climate over Korea from a double-nested regional climate model simulation. J Meteorol Soc Jpn 85:717-732

Im ES, Kwon WT (2007b) Characteristics of extreme climate sequences over Korea using a regional climate change scenario. Sci Online Lett Atmos 3:17-20

Joseph PV, Srinivasan J (1999) Rossby waves in May and the Indian summer monsoon rainfall. Tellus 51A:854-864

Kalnay E, Kanamitsu M, Kistler R, Collins W and others (1996) The NCEP/NCAR 40-year reanalysis project. Bull Am Meteorol Soc 77:437-470

Karl TR, Easterling DR (1999) Climate extremes: selected review and future research directions. Clim Change 42 : 309-325

Kiehl JT, Hack JJ, Bonan GB, Boville BA, Breigleb BP, Williamson D, Rasch P (1996) Description of the NCAR Community Climate Model (CCM3). Tech Rep NCAR/TN-420+STR, National Center for Atmospheric Research, Boulder, CO

Krishnan R, Zhang C, Sugi M (2000) Dynamics of breaks in the Indian summer monsoon. J Atmos Sci 57:1354-1372

Liu SC, Fu C, Shiu CJ, Chen JP, Wu F (2009) Temperature dependence of global precipitation extremes. Geophys Res Lett 36:L17702 doi:10.1029/2009GL040218

Manton MJ, Della-Marta PM, Haylock MR, Hennessy KJ and others (2000) Trends in extreme daily rainfall and temperature in Southeast Asia and the South Pacific: 1961-1998. Int J Climatol 21:269-284

McInnes KL, Hubbert GD (1996) Extreme events and the impact of climate change on Victoria's coastline: report to EPA and Melbourne Water. Publication 488, Environment Protection Authority, Melbourne

Meehl GA, Zweiers F, Evans J, Knutson K, Mearns L, Whetton P (2001) Trends in extreme weather and climate events: issues related to modeling extremes in projections of future climate change. Bull Am Meteorol Soc 81: 427-436

> Meehl GA, Washington WM, Santer BD, Collins WD and others (2006) Climate change projections for the twentyfirst century and climate change commitment in the CCSM3. J Clim 19:2597-2616

Nguyen DN, Nguyen TH (2004) Vietnamese climate and climatic resources. Hanoi Agriculture Press, Hanoi

> Pal JS, Small EE, Eltahir EAB (2000) Simulation of regionalscale water and energy budgets: representation of subgrid cloud and precipitation processes within RegCM. J Geophys Res 105:29579-29594

Pal JS, Giorgi F, Bi X, Elguindi N and others (2007) Regional climate modelling for the developing world: the ICTP RegCM3 and RegCNET. Bull Am Meteorol Soc 88: 1395-1409

Pham NT, Phan TD (1993) Vietnamese climate. Science \& Technique Press, Hanoi

> Phan VT, Ngo-Duc T, Ho TMH (2009) Seasonal and interannual variations of surface climate elements over Vietnam. Clim Res 40:49-60

> Pitman AJ, Perkins SE (2008) Regional projections of future seasonal and annual changes in rainfall and temperature over Australia based on skill-selected AR4 models. Earth Interact 12:1-50

Plummer N, Salinger MJ, Nicholls N, Suppiah R and others (1999) Changes in climate extremes over the Australian region and New Zealand during the twentieth century. Clim Change 42:183-202

Sánchez E, Gallardo C, Gaertner MA, Arribas A, Castro M (2004) Future climate extreme events in the Mediter- 
ranean simulated by a regional climate model: a first approach. Global Planet Change 44:163-180

Solomon S, Qin D, Manning M, Chen Z and others (eds) (2007) Climate change 2007: the physical science basis. Contribution of Working Group I to the Fourth Assessment Report of the Intergovernmental Panel on Climate Change. Cambridge University Press, Cambridge

Solow AR (1999) On testing for change in extreme events. Clim Change 42:341-349

Tompkins H (2002) Climate change and extreme weather events - is there a connection? Cicerone 3:1-5, available at www.cicero.uio.no/media/1862.pdf

Trenberth KE, Dai A, Rasmussen RM, Parsons DB (2003) The changing character of precipitation. Bull Am Meteorol Soc 84:1205-1217 doi:10.1175/BAMS-84-9-1205

Editorial responsibility: Filippo Giorgi, Trieste, Italy
Trenberth KE, Jones PD, Ambenje P, Bojariu R and others (2007) Observations: surface and atmospheric climate change. Climate change 2007: the scientific basis. Contribution of Working Group I to the Fourth Assessment Report of the Intergovernmental Panel on Climate Change. Cambridge University Press, Cambridge, p 235-336

Vietnamese Ministry of Natural Resources and Environment (2009) Report of sea level rising and climate change scenarios for Vietnam. Vietnamese Ministry of Natural Resources and Environment, Hanoi

VNWSC (Vietnamese National Weather Service Center) (2008) Annual Report 2008. Hanoi

Wisner B, Blaikie P, Cannon T, Davis I (2004) At risk: natural hazards, people's vulnerability and disasters, 2nd edn. Routledge, New York

Submitted: July 28, 2010; Accepted: June 7, 2011

Proofs received from author(s): September 19, 2011 